\title{
Efecto de reguladores de crecimiento en el establecimiento in vitro de Vasconcellea sp., a partir de meristemos apicales en Chachapoyas, Amazonas
}

\section{Effect of growth regulators in the in vitro establishment of Vasconcellea sp., starting from apical meristems in Chachapoyas, Amazonas}

Yoiner Kalin Lapiz Culqui' ${ }^{1}$, Eyner Huamán Huamán ${ }^{1}(\mathbb{D})$, Juan Carlos Neri Chávez ${ }^{1} \mathbb{D}$, Segundo Manuel Oliva Cruz ${ }^{1 *}(\mathbb{D}$

\section{RESUMEN}

La investigación tuvo como finalidad evaluar el efecto de reguladores de crecimiento en el establecimiento in vitro de Vasconcellea sp., a partir de meristemos apicales. Para ello, se usaron las variedades Babaco, Maushan y Papayita, las cuales fueron establecidas en ambientes de laboratorio. Se estableció un Diseño Completamente Aleatorio, con arreglo factorial. Cada especie se estableció con tres reguladores del crecimiento (ácido naftalen acético, ácido indol acético y ácido giberélico). Por tanto, se tuvieron nueve tratamientos con tres repeticiones de cada uno. Las variables evaluadas fueron número de explantes contaminados por hongos, número de explantes contaminados por bacterias, numero de explantes necrosados y número de explantes viables. Los resultados mostraron que los explantes del Papayita con ácido indol acético presentó los niveles más altos de necrosamiento. El Maushan con ácido naftalen acético y ácido indol acético, presentaron la mayor contaminación fúngica y bacteriana. Mientras que el Babaco con ácido giberélico presentó la mayor viabilidad al finalizar el establecimiento.

Palabras claves: ácido naftalen acético, ácido indol acético, ácido giberélico, meristemos, Vasconcellea sp.

\begin{abstract}
The research had as purpose to evaluate the effect of growth regulators in the establishment in vitro of Vasconcellea sp., from apical meristems. For this, the varieties Babaco, Maushan and Papayita were used, which were established in laboratory environments. A Completely Random Design was established, with a factorial arrangement. A Completely Random Design was established, with factorial arrangement. Each species was established with three growth regulators (naphthalene acetic acid, indol acetic acid and gibberellic acid). Therefore, nine treatments were had with three replicates of each. The variables evaluated were the number of explants contaminated by fungi, the number of explants contaminated by bacteria, the number of necrotic explants and the number of viable explants. The results showed that the Papayita explants with indol acetic acid presented the highest levels of necrosis. The Maushan with naphthalene acetic acid and indol acetic acid, presented the highest fungal and bacterial contamination. While Babaco with gibberellic acid presented the highest viability at the end of the establishment.
\end{abstract}

Keywords: naphthalene acetic acid, indol acetic acid, gibberellic acid, meristems, Vasconcellea sp.

\footnotetext{
${ }^{1}$ Universidad Nacional Toribio Rodríguez de Mendoza de Amazonas, Instituto de Investigación para el Desarrollo Sustentable de Ceja de Selva, Chachapoyas, Perú

Autor de Correspondencia, e-mail: soliva@indes-ces.edu.pe
} 


\section{INTRODUCCIÓN}

El género Vasconcellea es el más grande de la familia Caricaceae. Consta de 21 especies conocidas, procedentes del Centro y Sur de América (Robles-Carrión et al., 2016). En los últimos años, el cultivo de Vasconcellea ha tomado una mayor importancia debido a sus grandes propiedades tanto alimenticias, como por el uso de sus propiedades químicas en la industria. Dentro de los productos obtenidos a partir de su industrialización tenemos papaína, pectina, esencias, aceites, diversos medicamentos, néctares, conservas, miel, jalea, mermeladas, entre otros (Posada-Pérez, 2005). También es demandada por el látex, que contiene principalmente la papaína tanto en sus hojas, tallo y raíces, extendiendo así el uso como medicinas para el sistema digestivo, como ablandador y condimento en carnes, como clarificador de bebidas principalmente cervezas, así como en la industria de la curtiembre en la maceración de cueros (Granara, 2010). En la Región Amazonas existe una gran diversidad de estas especies, los cuales crecen en cercos o son sembrados en pequeñas áreas, por algunos productores, como una fuente de ingreso. En su mayoría no son tomadas como productos de interés debido al desconocimiento por parte de los pobladores, en consecuencia, se ha venido depredando de manera masiva sin realizar ninguna practica o labor para poder conservarlo. Esto ha provocado la disminución constante en su población. Uno de los factores que limitan su propagación, es la contaminación microbiana (bacterias y virus), sobre todo durante la propagación vegetativa. A esto hay que sumar, la poca viabilidad de las semillas que se producen. A pesar de que la reproducción vegetativa, es la técnica de propagación más utilizada para el género Vasconcellea, da lugar a problemas fitopatológicos (Espinosa, 2016). La necesidad de plantas de calidad, con características uniformes, bajo condiciones de crecimiento controlables deseables para el agricultor y la industria, han hecho ineludible el aporte de la biotecnología (Domínguez, 2016). Por lo tanto, una de las alternativas a estos problemas es la propagación in vitro. Sin embargo, para el establecimiento exitoso de estas especies, es necesa- rio prevenir y controlar la contaminación microbiana y oxidación fenólica, ya que constituye uno de los problemas más graves en la micropropagación de frutales leñosos (Germanà y Lambardi, 2015). Por ello, el objetivo de esta investigación fue establecer tres especies de Vasconcelleas mediante la propagación in vitro y así obtener una producción masiva de material de siembra, garantizando plantas libres de patógenos, para su posterior desarrollo en las siguientes etapas de micropropagación. Además de la conservación de dichas especies y de contar con un material de siembra disponible para la producción a gran escala y por ende tener una mayor producción en la Región Amazonas.

\section{MATERIALES Y MÉTODOS}

\section{Diseño experimental}

El diseño de experimento fue Diseño Completamente al Azar (DCA), con arreglo factorial de nueve tratamientos y tres repeticiones, teniendo como número de observaciones tres unidades visuales por tratamiento, haciendo un total de 81 plantas en todo el experimento. Para los tratamientos se usaron tres variedades de Vasconcellea, las cuales fueron Babaco, Maushan y Papayita. Por otro lado, los reguladores de crecimiento usados para el experimento fueron el ácido naftalen acético (ANA), ácido indol acético (AIA) y el ácido giberélico (AG) (Tabla 1). El experimento se realizó en el Laboratorio de Fisiología y Biotecnología Vegetal perteneciente al Instituto de Investigación para el Desarrollo Sustentable de Ceja de Selva (INDESCES) de la Universidad Nacional Toribio Rodríguez de Mendoza de Amazonas (UNTRM-A).

\section{Pretratamiento y desinfección de los explantes.}

Para el pretratamiento y desinfección se utilizó la metodología establecido por Jadán-Guerrero et al (2016). Se recolectaron 27 brotes de meristemos apicales de cada una de las tres variedades que fueron usados como explantes. Para el pretratamiento se estableció un control fitosanitario, el cual se realizó cuatro semanas previas a la toma del material vegetal. El control fitosanitario consistió en aplicar el fungicida Phyton (sulfato de cobre pentahidratado) a una dosis de 2,0 ml/1 y un 
Tabla 1. Descripción de los tratamientos con las especies de Vasconcellea y los reguladores de crecimiento usados

\begin{tabular}{cc}
\hline Tratamiento & Descripción \\
\hline T1 & Brotes de Maushan + ANA \\
T2 & Brotes de Maushan + AIA \\
T3 & Brotes de Maushan + AG \\
T4 & Brotes de Papayita + ANA \\
T5 & Brotes de Papayita + AIA \\
T6 & Brotes de Papayita + AG \\
T7 & Brotes de Babaco + ANA \\
T8 & Brotes de Babaco + AIA \\
T9 & Brotes de Babaco + AG \\
\hline
\end{tabular}

bioestimulante Gib-bex (Giberelinas) para estimular el crecimiento de los brotes. Las aplicaciones se realizaron por aspersión en el área foliar cada tres días.

Para la desinfección, se seleccionaron brotes de yemas apicales con un tamaño aproximado de tres a cinco $\mathrm{cm}$ que fueron cortados con la ayuda de una tijera de podar, previamente desinfectado con etanol al 70\% y luego fueron transportados al laboratorio. Previamente al establecimiento in vitro, a los brotes seleccionados se les elimino las hojas.

Ya en el laboratorio, se realizó un lavado con agua común bajo el grifo durante dos horas, después un lavado en una solución jabonosa a una dosis de 3,0 ml/1 durante 15 minutos, con agitación a $90 \mathrm{rpm}$ con un agitador orbital. Posteriormente, se realizaron tres lavados con agua destilada estéril, y se les sumergió en una solución de fungicida Phyton con una dosis de 1,5 $\mathrm{ml} / 1$ por 30 minutos con agitación a $90 \mathrm{rpm}$ con el agitador orbital. Luego, se realizó un lavado con agua destilada estéril, y se les sumergió en hipoclorito de sodio ( $\mathrm{NaCLO}$ ) a una concentración de 1,5\% durante 10 minutos. Después, los explantes se les mantuvo en agitación constantemente. A todos los tratamientos se les adicionó dos gotas de Tween 20 .

\section{Preparación del medio de cultivo}

En un vaso de precipitados de un litro, se añadió 1000 $\mathrm{ml}$ de agua destilada, 4,2 $\mathrm{g}$ de sales minerales Murashigue \& Skoog, 8,5 g de vitaminas, 2,0 g de carbón activado. Seguidamente se pesó $30,0 \mathrm{~g}$ de sacarosa y se agregó al medio. La mezcla se ajustó hasta un $\mathrm{pH}$ de 5,8 , para ello se hidróxido de sodio $(\mathrm{NaOH})$ o ácido clorhídrico $(\mathrm{HCl})$, con un pHmetro marca HANNA modelo HI9210. A continuación, se añadió 7,5 g de agar y los reguladores de crecimiento (ANA, AIA y AG) a concentraciones de $1,5 \mathrm{mg} / 1,0,5 \mathrm{mg} / 1$ y $0,3 \mathrm{mg} / 1$ respectivamente, disolviéndolo en un microondas. Luego se vertió $20 \mathrm{ml}$ de solución en cada tubo de ensayo y se esterilizó el medio en una autoclave durante $20 \min$ a $120^{\circ} \mathrm{C}$ y $1 \mathrm{Kg} / \mathrm{cm}^{2}$ de presión.

\section{Establecimiento in vitro}

Una vez desinfectadas las yemas apicales, con la ayuda de un estereoscopio marca Carl Zeiss modelo SteREO Discovery V8, se realizó la disección de los meristemos. Los explantes vegetales se colocaron sobre una placa Petri. Con la ayuda de un bisturí, se eliminaron los primordios foliares hasta dejar el meristemo descubierto. Finalmente, se realizó un corte en la base del meristemo y se introdujo en el tubo de ensayo con el medio de cultivo (Solis et al., 2011) Las plántulas fueron colocadas en condiciones de estricta asepsia, con tubos fluorescentes de luz blanca con un fotoperiodo de 12 horas luz y una densidad de flujo de fotones fotosintéticos de $16,8 \mu \mathrm{mol} / \mathrm{m}^{2} \cdot \mathrm{s}$. La humedad relativa del cultivo se estableció en un $50 \%$.

\section{Evaluación y análisis de datos}

El experimento se evaluó cada siete días durante un mes, evaluando el número de explantes con hongos $(\mathrm{NECH})$, el número de explantes con bacterias (NECB), el número de explantes viables (NEV) y el número de explantes necrosados (NEN).

Para el procesamiento de los datos se usó el análisis multivariado de análisis de componentes principales $(\mathrm{ACP})$, con el software estadístico Infostat versión 2018 (Di Rienzo et al., 2018).

\section{RESULTADOS}

En la primera evaluación, a los 7 días del establecimiento in vitro, se observa que la repetición tres del tratamiento siete presento un mayor nivel de necrosamiento. Mientras que la repetición dos del tratamiento nueve presento una mayor contaminación por bacterias. Así mismo, en la repetición tres del tratamiento dos se observó una mayor contaminación por hongos. Finalmente, la repetición uno del tratamiento seis presento la mayor viabilidad de explantes (Figura 1). 


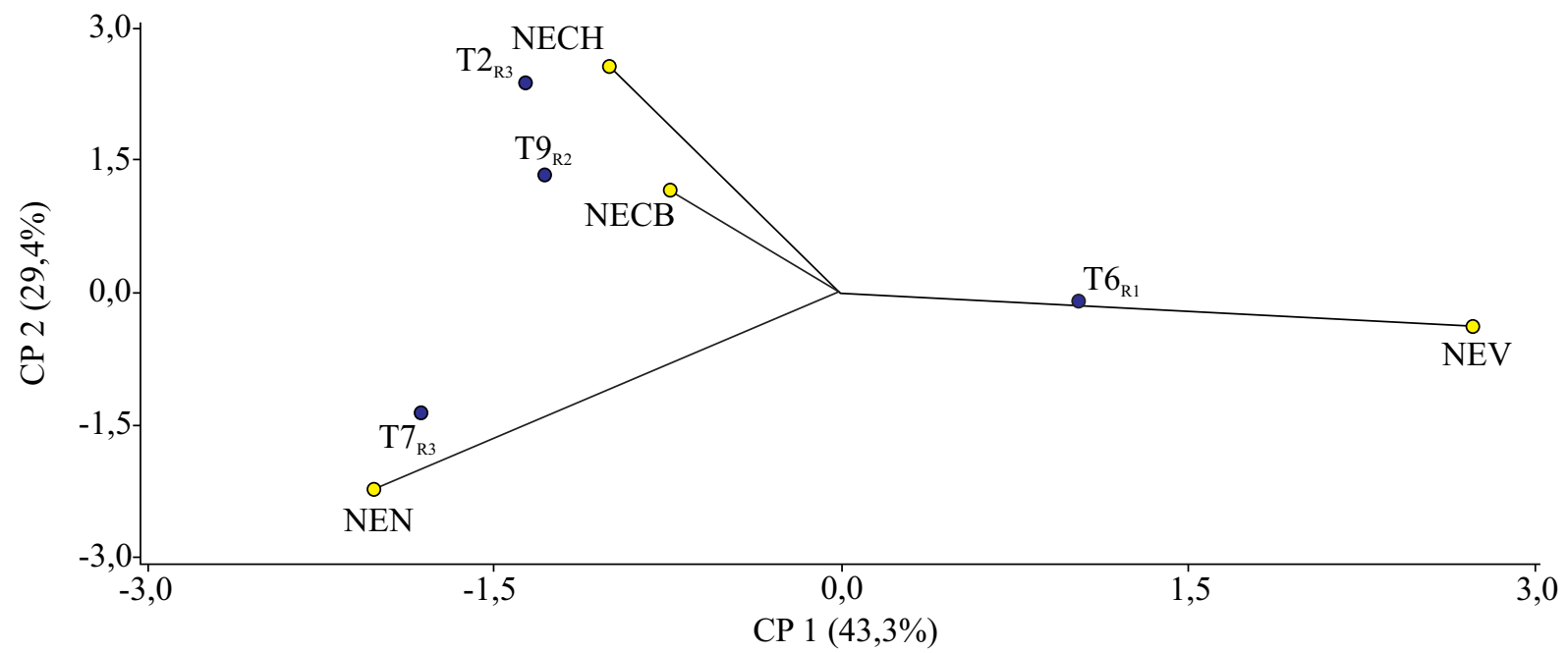

Figura 1. Variables evaluadas a los 7 días del establecimiento in vitro. $\left(\mathrm{CP}=\right.$ Componente principal; $\mathrm{NECH}=\mathrm{N}^{\circ}$ de explantes con hongos; $\mathrm{NECB}$ $=\mathrm{N}^{\circ}$ de explantes con bacterias; $\mathrm{NEV}=\mathrm{N}^{\circ}$ de explantes viables; $\mathrm{NEN}=\mathrm{N}^{\circ}$ de explantes necrosados, $\mathrm{R}=$ repetición).

Tras 14 días, se observó que la repetición tres del tratamiento dos presento un mayor necrosamiento. Además, la repetición dos del tratamiento nueve presento un mayor nivel de contaminación por bacterias. Así mismo, la repetición tres del tratamiento tres presento un mayor nivel de contaminación por bacterias. Finalmente, la repetición tres del tratamiento 9 tuvo un mayor índice de viabilidad (Figura 2).

Después de 21 días, se observó que la repetición dos del tratamiento cinco y la repetición tres del tratamiento cuatro presentaron un mayor índice de necrosamiento. Por otro lado, la repetición uno del tratamiento seis y la repetición tres del tratamiento cinco tuvieron los mayores niveles de contaminación bacteriana. Así mismo, la repetición tres del tratamiento tres y la repetición dos del tratamiento tres presentaron mayor contaminación fúngica. Por último, la repetición tres del tratamiento nueve presentó la mejor viabilidad (Figura 3).

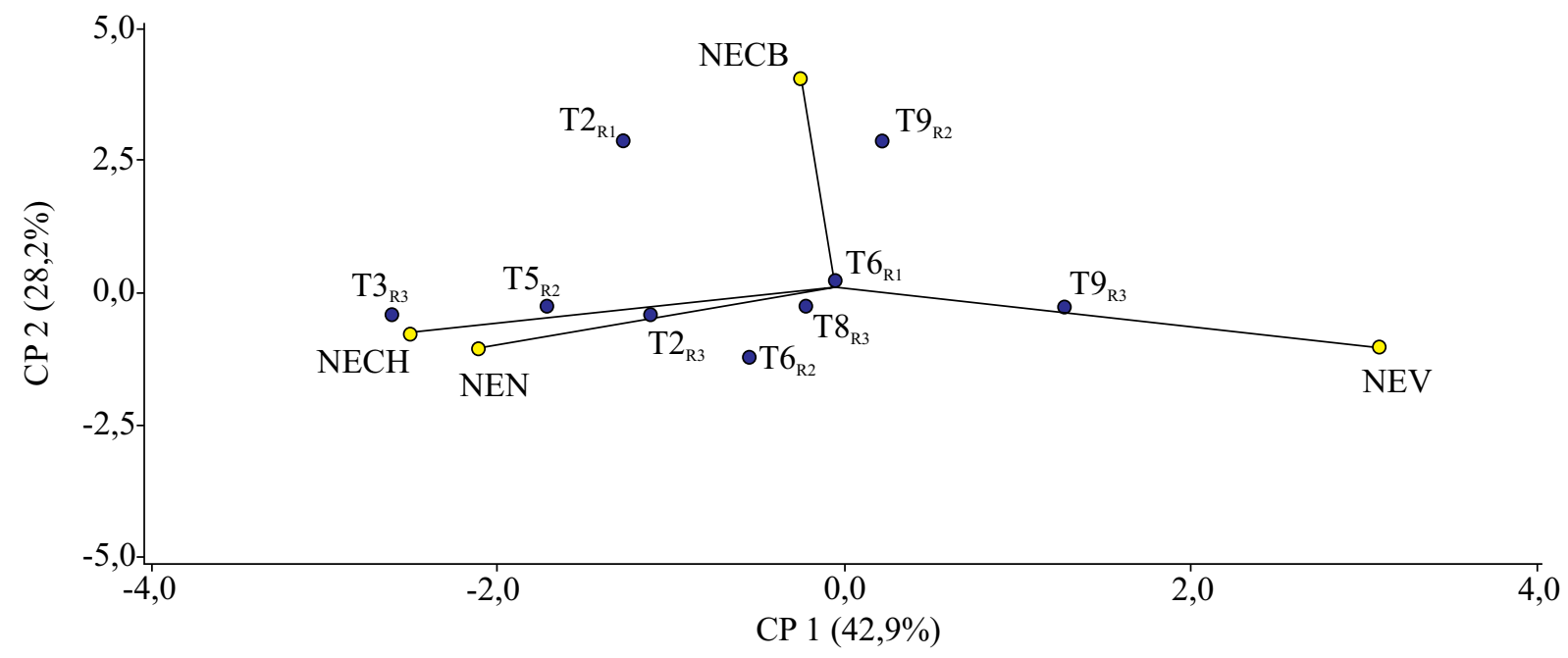

Figura 2. Variables evaluadas a los 14 días del establecimiento in vitro. $\left(\mathrm{CP}=\right.$ Componente principal; $\mathrm{NECH}=\mathrm{N}^{\circ}$ de explantes con hongos; $\mathrm{NECB}=\mathrm{N}^{\circ}$ de explantes con bacterias; $\mathrm{NEV}=\mathrm{N}^{\circ}$ de explantes viables; $\mathrm{NEN}=\mathrm{N}^{\circ}$ de explantes necrosados, $\mathrm{R}=$ repetición).

Al finalizar el establecimiento in vitro, los explante de la repetición dos del tratamiento cinco presentaron los niveles más altos de necrosamiento. Mientras que la repetición uno del tratamiento dos y la repetición dos del tratamiento nueve tenían la mayor contaminación por bacterias y por hongos. Finalmente, la repetición tres del tratamiento nueve presentó la mayor viabilidad (Figura 4).

\section{DISCUSIÓN}

Tras tres semanas de la instalación de los brotes de Vasconcellea, se comprobó que la repetición dos del tratamiento cinco, presento los niveles más altos de 


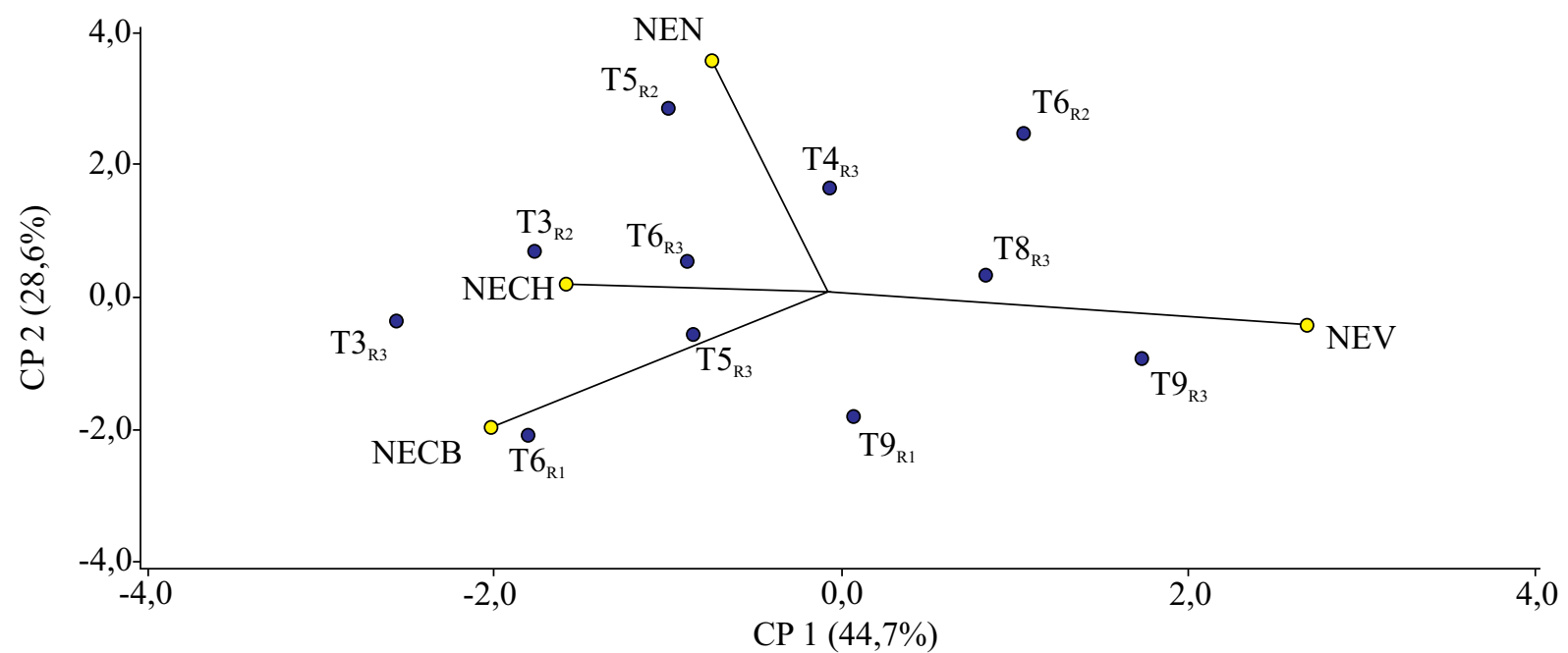

Figura 3. Variables evaluadas a los 21 días del establecimiento in vitro. $\left(\mathrm{CP}=\right.$ Componente principal; $\mathrm{NECH}=\mathrm{N}^{\circ}$ de explantes con hongos; $\mathrm{NECB}=\mathrm{N}^{\circ}$ de explantes con bacterias; $\mathrm{NEV}=\mathrm{N}^{\circ}$ de explantes viables; $\mathrm{NEN}=\mathrm{N}^{\circ}$ de explantes necrosados, $\mathrm{R}=$ repetición).

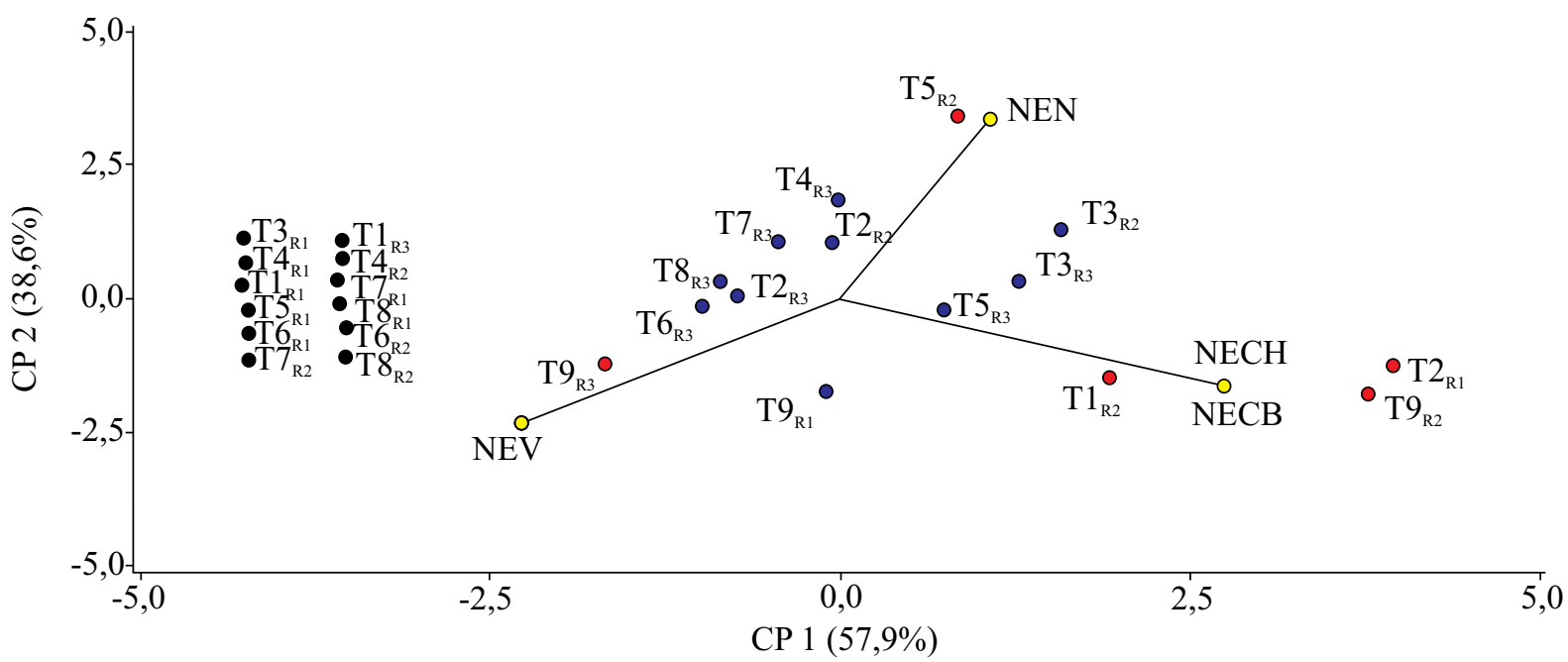

Figura 4. Variables evaluadas al final del establecimiento in vitro. $\left(\mathrm{CP}=\right.$ Componente principal; $\mathrm{NECH}=\mathrm{N}^{\circ}$ de explantes con hongos; $\mathrm{NECB}=$ $\mathrm{N}^{\circ}$ de explantes con bacterias; $\mathrm{NEV}=\mathrm{N}^{\circ}$ de explantes viables; $\mathrm{NEN}=\mathrm{N}^{\circ}$ de explantes necrosados, $\mathrm{R}=$ repetición).

necrosamiento. En este caso, se utilizó 1,5\% de hipoclorito de sodio por 30 minutos. Por lo que una de las causas del necrosamiento, podría ser el porcentaje de hipoclorito de sodio utilizado y el tiempo de inmersión para su desinfección. Con la concentración de hipoclorito de sodio $1,5 \%$, durante 10 minutos, se redujo en un $55 \%$ la contaminación por bacterias y un $3 \%$ la contaminación por hongos, demostrando la efectividad de este tratamiento, a pesar de observar un $10 \%$ de ápices necrosados (Jadán-Guerrero et al., 2016). Al finalizar el tiempo del experimento, se observó que la repetición uno del tratamiento dos y la repetición dos del tratamiento nueve presentó una mayor contaminación por bacterias y hongos, por lo que una de las actividades preliminares que se deben realizar es un pretratamien- to antes de recolectar los explantes utilizando un insecticida y un bioestimulante para así poder obtener brotes libres de patógenos. Gib-bex uno de los bioestimulantes utilizados ayudo a la elongación y proliferación de nuevos brotes obteniendo así una gran cantidad de estos. Sin embargo, la aplicación foliar de reguladores de crecimiento tuvo un efecto positivo en la formación de nuevos brotes axilares, dado por el efecto dominante de la yema apical en este cultivo (Posada-Pérez et al., 2004). Cabe señalar el efecto positivo del pretratamiento a las plantas madres con el fungicida carbendazim, dos semanas previas a la toma de los ápices en el proceso de desinfección con solución del fungicida DORBAQ (Jadán-Guerrero et al., 2016).

Los resultados de la viabilidad de los explantes a los 21 
días, se ve favorecido a las concentraciones que se utilizó para cada tratamiento. Pedranzini y Giorno (2016), trabajaron con una dosis de 0,167 y 0,330 ppm de AIA en el cual obtuvo los mejores resultados en la longitud de brote. Mientras que la longitud de brote disminuye conforme aumenta la concentración de auxinas. Al término de la investigación se observó las diferencias en cuanto a la elongación de cada uno de los brotes y de cada una de las especies. Sin embargo, no todos los brotes pueden elongarse en la misma proporción, ya que existe una respuesta heterogénea de las plantas a los factores de crecimiento, aunque las condiciones controladas sean iguales para todas (Posáda-Pérez et al., 2017).

\section{CONCLUSIONES}

La repetición tres del tratamiento nuevo, donde se usaron explantes de Babaco con ácido giberilico a una concentración de $0,3 \mathrm{mg} / \mathrm{l}$, presento mayor viabilidad al finalizar el establecimiento, logrando así seguir con la siguiente etapa de micropropagación.

La mortalidad de los explantes se debió al tiempo de inmersión en las distintas etapas de desinfección las cuales se vio reflejada con un necrosamiento de color marrón oscuro. Al mismo tiempo, la contaminación microbiana y fúngica se debió más al mal manejo al momento de realizar el establecimiento in vitro que por la contaminación endófita de los explantes. La mayoría de explantes fueron contaminados por bacterias que se insertaron al momento de realizar la siembra.

\section{REFERENCIAS BIBLIOGRÁFICAS}

Jadán-Guerrero, M., K. Basantez, R. Gómez-Kosky, y

I. Bermúdez-Caraballoso. 2016. "Establecimiento in vitro de brotes de Vasconcellea $x$ helbornii (Badillo) Badillo.” Biotecnología Vegetal 16(2): 67-72.

Di Rienzo J. A., F. Casanoves, M. G. Balzarini, L. Gonzalez, M. Tablada, y C. W. Robledo. 2018. InfoStat versión 2018. Centro de Transferencia InfoStat, FCA, Universidad Nacional de
Córdoba, Argentina.

http://www.infostat.com.ar.

Domínguez, K. M. 2016. Evaluación de la embriogénesis somática de "papaya de alta montaña" Vasconcellea pubescens a partir de embriones cigóticos. Tesis de Grado. Universidad De Las Américas. Quito (Ecuador).

Espinosa, I. 2016. Germinación, microinjertacion y cultivo de callos in vitro de Vasconcellea stipulata V.M. Badillo y Vasconcellea pubescens A.DC.» Tesis de Maestría. Universidad Nacional de La Plata. La Plata (Argentina).

Germanà, M. A. y M. Lambardi. 2015. In Vitro Embryogenesis in Higher Plants. Nueva Jersey (EE.UU.): Humana Press.

Granara, J. C. 2010. Nuevos alcances en los productos derivados de la papaya. Tesis de Grado. Universidad Nacional de Ingeniería. Lima (Perú).

Hernández, Y. y M. E. González. 2010 “Efectos de la contaminación microbiana y oxidación fenólica en el establecimiento in vitro de frutales perennes." Cultivos Tropicales 31 (4): 1-19.

Posada-Pérez, L. 2005. "Aplicaciones de la biotecnología a la propagación de la papaya." Biotecnología Vegetal 5 (2): 67-79.

Posada-Pérez, L., R. Gómez-Koskoy, J. Gallardo, M. Reyes, y I. Herrera. 2004. "Establecimiento in vitro de ápices de plantas de campo del híbrido cubano de Papaya IBP 42-99." Biotecnología Vegetal 4 (3): 153-158.

Posada-Pérez, L., Y. P. Montesinos, D. G. Guerra, D. Daniels, y R. Gómez-Kosky. 2017. “Complete germination of papaya (Carica papaya L. cv. 'Maradol Roja') somatic embryos using temporary immersion system type RITA ${ }^{\circledR}$ and phloroglucinol in semi-solid culture médium.” In Vitro Cellular \& Developmental Biology-Plant 53: 505-513.

Robles-Carrión, A. R., L. Herrera-Isla, y R. TorresGutiérrez. 2016. "El babaco (Vasconcellea heilbornii var. pentagona Badillo). Principales agentes fitopatógenos y estrategias de 
control." Centro Agrícola 43 (2): 83-92.

Solis, R., J. Olivera, y R. S. La Rosa. 2011. "Propagación in vitro de Carica papaya var. PTM-331

a partir de meristemos apicales." Revista Peruana de Biología 18 (3):343-347. 